Jelena Kleut*

UDK 77.03:364.56(497.11) '2016/2017”

Brankica Drašković**

316.774:364.56

Filozofski fakultet

DOI: 10.19090/gff.2017.2. 165-183

Univerzitet u Novom Sadu

Originalni naučni rad

\title{
VIZUELNE REPREZENTACIJE IZBEGLICA NA "BALKANSKOJ RUTI" U MEDIJIMA U SRBIJI****
}

U radu analiziramo predstavljanje izbeglica na „Balkanskoj ruti“ u televizijskoj slici i novinskoj fotografiji. Rad ima za cilj da istraži kako se izbeglice predstavljaju u zemlji u kojoj izbeglička kriza nije politizovana i da ispita kako se izbeglice predstavljaju u različitim modalitetima - putem statičnih i pokretnih slika. Uzorak od 125 tekstova i televizijskih priloga prikupljen je tokom sedam dana u martu 2016. godine i tokom marta 2017. godine iz onlajn izdanja novina Blica i Politike, i večernjih dnevnika Radio-televizije Srbije i TV N1. Metoda vizuelne analize zasnovana je na Kresovoj i Van Lijuvenovoj vizuelnoj gramatici, i posebno na analizi vizuelnih toposa predstavljanja. U pogledu narativnih obrazaca predstavljanja identifikuje se pet toposa: drama, kretanje, primanje pomoći, higijena i igra. U konceptualnim obrascima pojavljuju se toposi porodice, dece, usamljenosti, žice i simboličke drugosti. Pozitivnije nego u drugim zemljama, ove su vizuelne predstave izbeglica su kontradiktorne - iako pozivaju na saosećaje i dalje konstruišu drugost i razlike između ,nas“ i ,njih“.

Ključne reči: kritička analiza diskursa, multimodalnost, novinska fotografija, televizijska slika, izbeglice, Srbija

\section{UVOD}

Srbija uz Grčku, Makedoniju i Hrvatsku postaje tokom 2015. godine delom najvažnijeg kopnenog tranzitnog puta prema Zapadnoj Evropi velikog broja izbeglica i migranata uglavnom iz Azije i Afrike, koji u političkom i medijskom

\footnotetext{
*jelena.kleut@ff.uns.ac.rs

*** brankica.draskovic@ff.uns.ac.rs.

*** Rad je nastao u okviru projekta III 47020 ,Digitalne medijske tehnologije i društvenoobrazovne promene“, koji se realizuje uz podršku Ministarstva prosvete, nauke i tehnološkog razvoja Republike Srbije i projekta „Kulturno nasleđe i identitet u kontekstu modernizacijskih procesa i sociokulturnih i tehnoloških promena"

koji je finansiran od strane Pokrajinskog sekretarijata za nauku i tehnološki razvoj (br. 114451-2790/2016-01). Ranija verzija ovog rada predstavljena na konferenciji "Vjerodostojnost medija" koja je organizovana maja 2016. godine na Fakultetu političkih nauka u Zagrebu.
} 
diskursu dobija naziv „Balkanska ruta“. Do usmeravanja izbeglica i migranata na putovanje duž balkanskih granica došlo je iz bezbednosnih razloga nakon višegodišnjih dramatičnih događaja na mediteranskim obalama Italije, do kojih su se, bežeći uglavnom od ratnih događaja i siromaštva u svojim zemljama, prebacivali brodovima i čamcima, i često nesretno okončavali živote. Prema podacima Ministarstva za rad, koji su nedavno predstavljeni javnosti, od početka izbegličke krize, maja 2015. godine, kroz Srbiju je prošlo milion ljudi. Trenutno u njoj boravi između 6.000 i 7.000 migranata, od toga 980 dece bez roditelja i 3.000 maloletnika, a njih 1.700 je zatražilo azil ("Pozitivan stav...", 2017).

Medijskim izveštajima o izbeglicama i migranatima na takozvanoj „Balkanskoj ruti“ pridaje se veliki značaj u kreiranju javnog menja. Površan i senzacionalistički pristup navodi se kao jedan od glavnih uzročnika stvaranja uglavnom negativnog odnosa građana Srbije (Vuletić et al., 2016), ali i Hrvatske (Lalić, 2016) i drugih zemalja koje se suočavaju sa najvećom migracijom ljudi koja se dogodila nakon Drugog svetskog rata. ${ }^{1}$ Prema prošlogodišnjem istraživanju koje je sproveo Centar za primenjena društvena istraživanja medijsko izveštavanje je „dosta ili presudno" uticalo na mišljenje građana Srbije o izbegličkoj krizi. Grupa autora koja je sprovela istraživanje smatra da je senzacionalističko izveštavanje medija koje je, kako se ističe, ,imalo funkciju buđenja kako pozitivnih tako i negativnih emocija“ prema izbeglicama bez analitičkog pristupa uslovilo „značajnu konfuziju u stavovima građana prema čitavoj problematici“ izbegličke krize (Vuletić et al., 2016: 13).

Od samog početka neusklađena je terminologija kojom se kriza naziva kako u medijima tako i u političkom diskursu. Bez obzira što najveći broj ljudi dolazi iz ratom zahvaćenih zemalja pre svega iz Sirije, Avganistana, Iraka, Somalije (UNHCR, 2016) koji bi prema međunarodnom pravu trebalo da se nazivaju izbeglicama ovaj termin se vrlo malo upotrebljava. U gotovo svim medijima, ne samo srpskim nego i stranim, stotine hiljada ljudi koji dolaze u Evropu mnogo češće se nazivaju migrantima (ilegalnim, nelegalnim, ekonomskim), azilantima, imigrantima. Ova kakofonija delimično je posledica neznanja novinara i njihovog samovoljnog tumačenja leksičke identifikacije u kojoj je vrlo često ulogu imala i ideološka matrica podele na dobre izbeglice i loše migrante, odnosno onih koji dolaze opravdano i one koji dolaze „neopravdano“. Mnogi evropski zvaničnici nazivaju je „migrantskom krizom“ kako bi sa sebe skinuli odgovornost koju prema međunarodnim konvencijama imaju prema izbeglicama. U radu se opredeljujemo za termin izbeglice koji prema našem mišljenju adekvatnije opisuje ljude koji

\footnotetext{
${ }^{1}$ Procenjuje se da je od početka krize oko 65 miliona ljudi napustilo svoje domove.
} 
prolaze Srbijom i koji upućuje na univerzalni humani tretman bez obzira na razloge koji stoje iza odluke da se krene put "Balkanske rute".

\section{MEDIJSKO PREDSTAVLJANJE IZBEGLICA - PREGLED ISTRAŽIVANJA}

Medijsko izveštavanje o izbeglicama čest je predmet istraživanja, a razlog tome može se pronaći u činjenici da od kraja prošlog veka u zemljama Zapada ova tema dolazi u središte političkih diskusija i ima značajno mesto u pozicioniranju političkih stranaka, posebno populističke desnice. Stoga se najveći deo istraživanja bavi situacijom u Austriji (Reisigl \& Wodak, 2001; Rheindorf \& Wodak, 2017), Velikoj Britaniji (Baker et al., 2008; Banks, 2012; Khosravinik, 2010), Nemačkoj (Holmes \& Castaneda, 2016), Italiji (Colombo, 2017; Richardson \& Colombo, 2013), Španiji (Alonso Belmonte, McCabe, \& Chornet-Roses, 2010; Martinez Lirola, 2014) i Australiji (Lenette \& Cleland, 2016). Nešto je manje komparativnih studija (Caciedes, 2015; Berry et al., 2016), koje pokazuju da, iako u većini zemalja mediji uglavnom negativno predstavljaju izbeglice, ipak postoje određene razlike. Na primer, izveštaj za UNHCR kojim su obuhvaćene Italija, Španija, Švedska, Nemačka i Britanija pokazuje da je švedska štampa naklonjenija izbeglicama dok su u Velikoj Britaniji najzastupljeniji negativni stavovi (Berry et al., 2016: 10).

Prema teorijsko-metodološkim polazištima, u relativno velikom korpusu mogu se uočiti tri pravca - analiza medijskih okvira (engl. framing), kritička analiza diskursa i vizuelna analiza. Teorija medijskog uokvirivanja podrazumeva da obimom izveštavanja i izborom pojedinih dimenzija događa, ljudi i procesa mediji formiraju javno mnjenje, odnosno utiču na percepciju događaja, njegovog značaja i ponuđenih rešenja (Scheufele, 1999). U kontekstu izbeglica u Francuskoj, Italiji i Velikoj Britaniji, Kavides (Caviedes, 2015) uočavaju dva okvira - ekonomski i bezbednosni. Unutar bezbednosnog, izbeglice se predstavljaju kao fizička pretnja, u kontekstu terorističkih napada i kriminala, kao i u smislu obezbeđivanja granica. Podjednako negativni, ekonomski okvir pojavljuje se onda kada se dolazak izbeglica dovodi u vezu sa kretanjima na tržištu rada, troškovima boravka i dodeljivanja azila. Holms i Kastaneda konstatuju da se migranti i izbeglice najčešće prikazuju kao „ekonomski oportunisti“ (Holmes \& Castaneda, 2016: 15), te da medijske predstave variraju između „konstituisanja onih koji su (ne)dostojni prijema i ksenofobije“ (Holmes \& Castaneda, 2016: 15).

Prateći prethodne studije o retorici diskriminacije (Reisigl \& Wodak, 2001), u oblasti kritičke analize diskursa najobimnije istraživanje sproveo je tim okupljen oko austrijske lingvistkinje Rut Vodak na Univerzitetu u Lankasteru. Kombinacijom kritičke analize diskursa i korpusne lingvistike, analiziran je 
medijski i vanmedijski diskurs u Velikoj Britaniji, u periodu od 1996. do 2006. godine. Jedan od zaključaka istraživanja jeste da se različiti nazivi - izbeglice, tražioci azila, imigranti i migranti - koriste kao sinonimi iako imaju drugačije pravne konsekvence (Baker et al, 2008: 283). U medijskom diskursu preovlađuje negativna perspektivizacija, zasnovana na diskursnom konstruisanju razlika između „nas“ i „njih“, a među najzastupljenijim topoima je topos brojeva, koji zajedno sa vodenim metaforama (,reka“, „poplava“, „talas“) naglašava masovnost dolazaka kao pretnju lokalnom životu (Baker et al., 2008). Pored ovog, pojavljuju se još i topos ekonomskog tereta, topos pretnje, topos opasnosti i topos zakona (Baker et al., 2008; Khosravinik, 2010). U predstavljanju izbeglica identifikovane su strategije agregacije, kolektivizacije i funkcionalizacije kao „lingvistički procesi kojima se ove grupe ljudi sistematski predstavljaju i konstruišu kao homogena grupa sa sličnim karakteristikama, pričama, namerama, motivacijama i ekonomskim statusom ili se svode na funkcije, npr. "oni koji ulaze"“" (Khosravinik, 2010: 13).

Vizuelna reprezentacija izbeglica ima poreklo u hrišćanskoj ikonografiji (Wright, 2002), posebno kada se naglašava ljudska patnja. Međutim, predstavljeni kao pretnja, savremene izbeglice su dekontekstualizovane, a retko se koriste krupni kadrovi sa prikazima lica (Bischoff, Falk \& Kafehsy, 2010). U medijima preovlađuju slike muškaraca u grupama i slike prenatrpanih brodova, napravljene iz perspektive Evropljana, kako dolaze ka "nama" - gledaocima, koje se mogu interpretirati kao vizuelne metafore invazije (Horsti, 20116: 10).

Analiza novinskih fotografija pokazuje da se imigranti predstavljaju kao drugačiji od nas (strategija distanciranja), kao inferiorni, siromašniji i manje moćni (strategija obespravljivanja) i kao predmeti (strategija objektivacije) (Martinez Lirola, 2014: 18). Kako pišu Blejker i i saradnici: „Vizuelnim obrascima se izbeglice predstavljaju kao 'problem' - ne kao humanitarna katastrofa koja zahteva saosećajni odgovor javnosti, već kao pretnja koja pokreće mehanizme odbrane i kontrole granica. Ovi dehumanizujući vizuelni obrasci direktno podstiču politiku straha“ (Bleiker et al, 2013: 399). Do sličnog zaključka dolazi i Manik koja konstatuje da ,vizuelne predstave izbeglica obezvređuju njihovu patnju jer prikrivaju, komodifikuju i senzacionalizuju individualno i stvarno iskustvo patnje“ (Mannik, 2012: 264).

Čestu temu u vizuelnoj analizi čini prikaz lika izbeglice. Saosećanje izazivaju slike žena i dece, o čemu Linet i Kliland pišu u kontekstu rastuće „feminizacije slika“ (Lenette \& Cleland, 2016). U negativnom kontekstu, izbeglice se predstavljaju u ključu ,vizuelnog disfemizma“ jer se ,pežorativne odlike tabua naglašavaju sa ciljem vređanja“ (Martinez Lirola, 2014: 420). Slično i Benks piše o tri „vizuelna scenarija“: 
,prvo, bezlični i de-identifikovani stranac omogućava konstrukciju prikaza zastrašujućih subjekata. Drugo, stigma se implicitno ilustruje, devijantnost se suptilno signalizira i 'spolied identiteti' konstruišu se. Treće, maske se skidaju i tražilac azila je identifikovan i njegov devijantni status potvrđuje se. Ovaj proces se uz manje modifikacije ponavlja u vestima, a devijantnost postaje utkana u sliku tražioca azila“" (Banks, 2012: 293).

U odnosu na dosadašnja istraživanja ovaj rad ima dva cilja. Prvo, da istraži kako se izbeglice predstavljaju (vizuelnim izrazom) u zemlji u kojoj izbeglička kriza nije istaknuto pitanje političke debate i u kojoj ne postoje političke stranke koje jasno artikulišu anti-imigrantske pozicije. Drugo, cilj je da se ispita kako se izbeglice predstavljaju u različitim modalitetima - posredstvom statičnih i pokretnih slika - te da se na taj način dopuni postojeći korpus studija koje se preovlađujuće bave fotografijama.

\section{METODE ISTRAŽIVANJA}

U radu koristimo kritičku analizu diskursa (KAD), ne kao metodu već kao širi pristup građi (Baker et al., 2008: 274) koji omogućuje da se propita kako se dominacija, diskriminacija, moć i kontrola stvaraju i obnavljaju u diskurzivnim praksama (Reisigl \& Wodak, 2001; Van Dijk, 1988, Van Leeuwen, 2008). Srodna KAD-u nastaje i socijalna semiotika koja pojmovni aparat diskursne analize primenjuje na različite nejezičke modalitete (Hodge \& Kress, 1988; Kress, 2010; Kress \& Van Leeuwen, 2001; Kress \& Van Leeuwen, 2006; Manchin, \& Mayr, 2012; O'Halloran, 2004). Polazište socijalne semiotike jeste da su svi, pa i vizuelni znaci, motivisani sklopovi oznaka (formi) i označenih (sadržaja, značenja), te da umesto o kodovima treba govoriti o semiotičkim resursima koji imaju različite potencijale da iskažu značenja.

Formulišući „vizuelnu gramatiku“, Kres i Van Lijuven kreću od stava da „poput lingvističkih struktura, vizuelne strukture upućuju na određene interpretacije iskustva i forme društvene interakcije“ (Kress \& Van Leeuwen, 2006: 2). U prevođenju jezičkih u nejezičke kategorije, oslonac pronalaze u Halidejevim metafunkcijama jezika - ideacionoj, interpersonalnoj i tekstualnoj. Pod ideacionom funkcijom razumeju ,sposobnost semiotičkih sistema da predstavljaju objekte i njihove odnose u svetu izvan sistema reprezentacija ili u semiotičkim sistemima kulture“ (Kress \& Van Leeuwen, 2006: 47). Dakle, u analizi vizuelnih sadržaja u odnosu na ideacionu funkciju postavlja se pitanje na koji način su predstavljeni ljudi, događaji i predmeti, i kako se vizuelnim ,jezikom“ određuju relacije između njih. U ovim obrascima predstavljanja autori razlikuju narativne procese i 
konceptualne predstave, koji uslovno odgovaraju dinamičkim i statičnim prikazima. „Dok konceptualni odnosi predstavljaju učesnike u pogledu klase, strukture ili značenja, drugim rečima u smislu uopštenih i manje ili više stabilnih i vanvremenskih odlika, narativni obrasci služe da predstave razvoj radnje i događaje, procese promene, tranzitne prostorne rasporede“ (Kress \& Van Leeuwen, 2006: 59).

Interpersonalna funkcija upućuje na to da se u realizaciji semiotičkih modaliteta stvaraju odnosi između pošiljalaca i primalaca, kao i između primalaca $i$ ljudi koji su vizuelno predstavljeni. Radi se, zapravo, o dve grupe učesnika (predstavljenih i interaktivnih, koji komuniciraju posredstvom slika) i o tri vrste odnosa: 1) odnosi između predstavljenih učesnika, 2) odnosi između interaktivnih i predstavljenih učesnika i 3) odnosi između interaktivnih učesnika (Kress \& Van Leeuwen, 2006: 114). Pod tekstualnom funkcijom razume se sposobnost svakog semiotičkog modaliteta da ,formira tekstove, skupove znakove koji su koherentni interno i eksterno, kao sa kontekstom u kom su stvoreni“ (Kress \& Van Leeuwen, 2006: 43). Analiza realizacije tekstualne funkcije upućuje na odnose između različitih modaliteta poruke, kao i na odnose koji se uspostavljaju među elementima unutar jednog modaliteta.

U radu će biti predstavljen deo analize koji se bavi ideacionom funkcijom, dok će ostala dva analitička elementa imati pomoćnu svrhu pri diskusiji o konkretnim primerima. Prateći pojmovnik vizuelne gramatike reprezentacije izbeglica grupisane su u narativne i konceptualne obrasce predstavljanja. Kada se radi o fotografijama, dva obrasca se uglavnom uzajamno isključuju, dok u televizijskim prilozima oni često sadejstvuju kao kombinacija statičnih i dinamičnih kadrova, odnosno sekvenci kao skupa kadrova kojima je zajednička tema ili postupak. Unutar dve grupe vizuelnih reprezentacija, u svrhe analize deduktivno je kreiran inventar toposa koji imaju zajedničke sadržinske i formalne odlike. U analizi diskursa topici se opisuju kao rezervoari uopštenih glavnih ideja iz kojih nastaju određene izjave ili argumenti (Richardson \& Colombo, 2013: 183), i posreduju između opštih kognitivnih struktura, kao prethodnog znanja učesnika komuniciranja, i konkretnih realizacija semiotičkih potencijala. Topos nije tema makro-tema u smislu u kom Van Dejk analizira medijski diskurs (Van Dijk, 1988), posebno kada se radi o vizuelnom izrazu koji se pojavljuje zajedno sa verbalnim. Ovakvom tumačenju vizuelnih topika ide u prilog i činjenica da se pojedini snimci ili fotografije pojavljuju u više, tematski različitih tekstova ili televizijskih priloga.

Korpus televizijskih slika i novinskih fotografija prikupljen je periodu od 11. do 17. marta 2016. godine iz onlajn izdanja dnevnih listova Blic i Politika, kao i iz večernjih dnevnika Radio-televizije Srbije i TV N1 koji se emituju u 19.30 
časova. U drugom ciklusu, period uzorkovanja je činio ceo mesec mart 2017. godine. Onlajn uzorak je formiran tako da budu zastupljene dve uredničke koncepcije - tabloidna i netabloidna, dok je televizijski uzorak formiran tako da obuhvati javni TV servis i komercijalnu televiziju. Uzorkovani su samo oni tekstovi i prilozi koji sadrže prikaze izbeglica na „Balkanskoj ruti“. Samih tekstova je bilo i više, ali njih 12 nije uopšte imalo fotografije dok u 39 tekstova fotografije ne prikazuju izbeglice već političare.

Tabela 1: Pregled uzoraka

\begin{tabular}{|l|l|}
\hline & $\begin{array}{l}\text { Broj } \\
\text { tekstova/priloga }\end{array}$ \\
\hline Blic (2016) & 53 \\
\hline Blic (2017) & 27 \\
\hline Politika (2016) & 15 \\
\hline Politika (2017) & 7 \\
\hline RTS (2016) & 7 \\
\hline TV N1 (2016) & 10 \\
\hline TV N1 (2017) & 6 \\
\hline UKUPNO & 125 \\
\hline
\end{tabular}

$\mathrm{Na}$ ovaj način kreiran uzorak sastoji se od 223 fotografija koje su objavljene u 102 teksta, kao i od 23 televizijskih priloga (Tabela 1). Ovde treba dodati da je broj pojedinačnih fotografija manji jer se pojedine slike pojavljuju u više tekstova. Očekivano, sa smanjenjem broja izbeglica i delimičnim zatvaranjem "Balkanske rute", broj tekstova i priloga je manji u 2017. godini u odnosu na posmatrani period iz 2016. godine, kada su analizirani mediji objavljivali po dve vesti dnevno.

\section{REZULTATI ISTRAŽIVANJA}

Narativni obrasci predstavljanja

Analiza pokazuje da su najčešći narativni obrasci oni kojima se predstavlja kretanje i drama, potom primanje pomoći i u manjoj meri igra i higijena. Topos kretanja čine grupne ili masovne fotografije i snimci, na kojima su izbeglice prikazane u pokretu, jedni iza drugih, pri čemu ljudska tela čine liniju koja pokretu daje pravac. Dve realizacije ovog toposa prikazane su na Slici 1 i Slici 2. Na prvoj pravac kretanja je ka „nama“, gledaocima, dok na drugoj pravac s leva na desno nema odredište već prati liniju horizonta. Fotografijama je zajedničko kolektivno i 
agregirano predstavljanje nosilaca radnje, a lica izbeglica se ne prikazuju, što doprinosi depersonalizaciji prikaza. Ovakve reprezentacije mogu se posmatrati kao pandani već identifikovanom toposu brojeva u tekstualnim strategijama (Baker et al., 2008). Posebno Slika 1 na metaforičkom planu odražava ideju toka, takođe zastupljenu u verbalnim opisima ,reke izbeglica“.

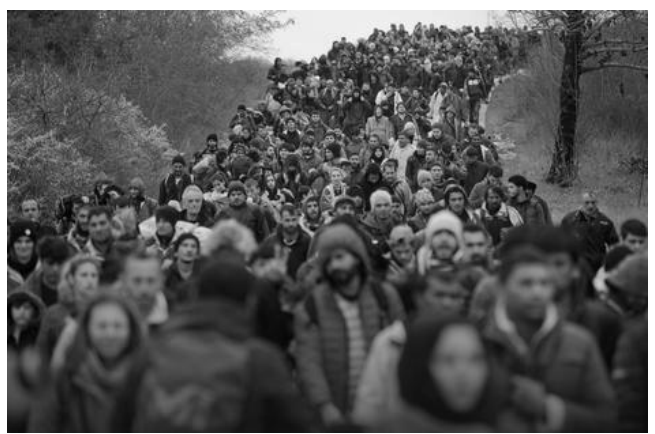

Slika 1. Topos kretanja

(Blic, 15. 3. 2016)

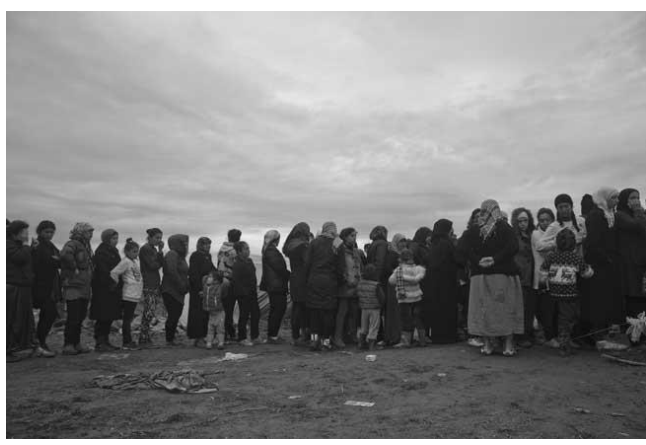

Slika 2. Topos kretanja

(Politika 12. 3. 2016)

Topos drame pronalazimo u fotografijama i televizijskim slikama koje kompozicijom i predstavljanjem radnje ukazuju na konflikt ili napetost. I za ovaj topos je karakteristično predstavljanje izbeglica u grupama. Slika 3, koja se pojavljuje $u$ pet različitih tekstova, primer je fotografije u kojoj napetost proizilazi iz kompozicije tri elementa - izbeglica iza ograde, policajca ispred ograde - čiju poziciju deli i čitalac - i same ograde. Transakcioni vektor interakcije stvara se između izbeglice u žutoj majici, čiji pogled je usmeren ka policajcu, a njihovi odnosi naglašeni su razlikom između tiskajuće mase razdrljenog odela i stroge urednosti predstavnika države.

Dramatizacija kao strategija reprezentovanja izbeglica često se javlja zajedno sa topoima kretanja i primanja pomoći (Slika 4 i Slika 6), i u ovim slučajevima drama se naglašava prikazima lica. Slike na denotativnom planu već označavaju dramatičnu radnju, ali ona drama se ističe - kontrastom između šarenila dečijeg odela i sivila šume, reke i odela odraslih na Slici 4, i proksemijom glava i ruku, njihovom brojnošću u odnosu na oskudnu pomoć oko koje se bore na Slici 6 . 


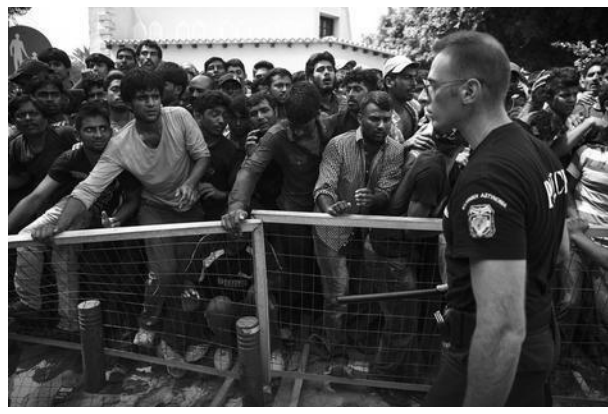

Slika 3. Topos drame

(Blic 11.3. 2016, 12. 3. 2016, 12. 3. 2016, 12. 3. 2016, 15. 3. 2016)

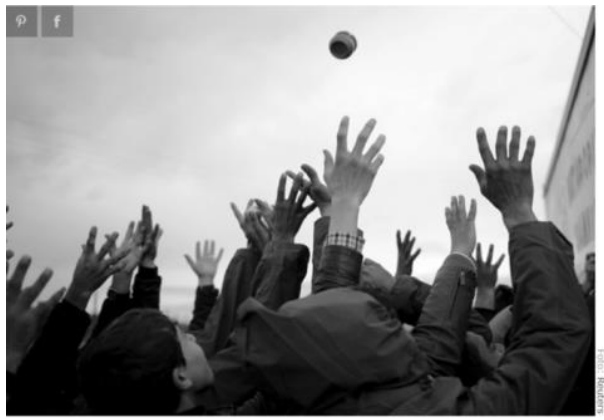

Slika 5. Topos pomoći

(Blic 11.3.2016, 11.3.2016)

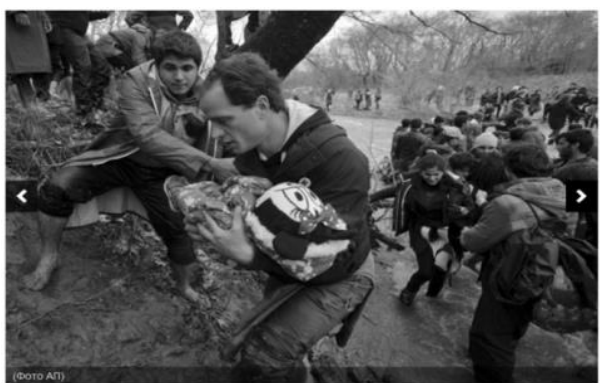

Slika 4. Topoi drame i kretanja (Blic, 11. 3. 2016, 12.3. 2016, 12. 3. 2016, 12. 3. 2016, 15. 3. 2016, Politika, 14. 3. 2016)

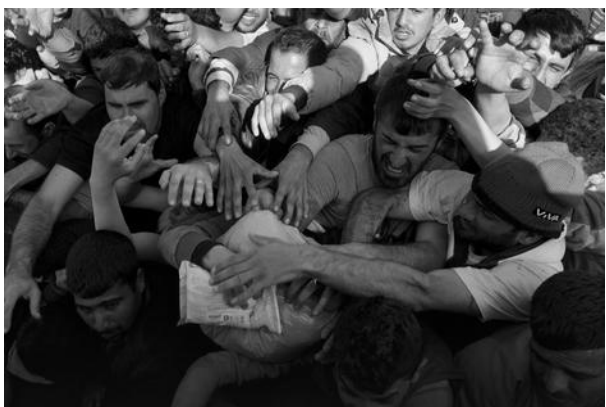

Slika 6. Topoi drame i pomoći (Blic 11. 3. 2016, 15. 3. 2016, 16.3.2016)

Topos primanja pomoći karakteriše građenje transakcionog odnosa između uvek eksplicitno reprezentovanih primalaca i često isključenih davalaca pomoći. $\mathrm{Na}$ Slikama 5 i 6, iako nude različite rakurse pa stoga i različite pozicije gledaoca, oni koji donose pomoć su izostavljeni iz kadra, tek implicirani kao učesnici radnje. Na obe slike, sama pomoć se predstavlja kao oskudna, a potražnja za njom velika.

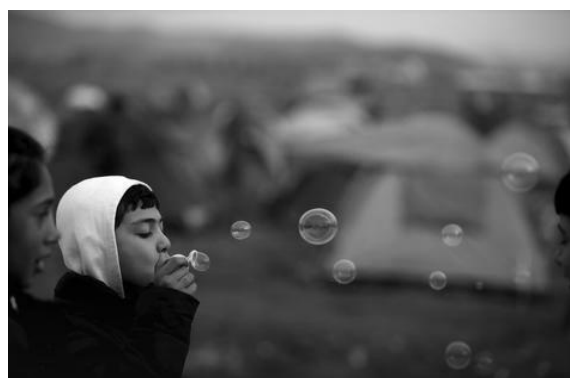

Slika 7. Topos igre

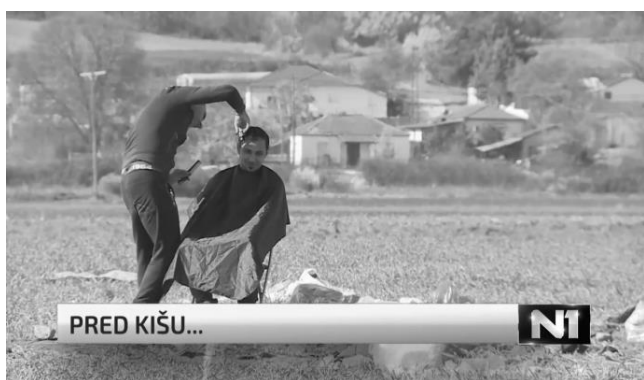

Slika 8. Topos higijena 
(Blic, 13. 3. 2016, 15.3.2016)

(Vesti u 19.30, N1, 11. 3. 2016.

Topos igre (Slika 7) i topos higijene (Slika 8) odudaraju od prethodno diskutovanih vizuelnih reprezentacija. Prvo, fotografije i televizijske slike ovih toposa su svetlije i oštrije. Potom, na njima su izbeglice prikazane pojedinačno ili u manjim grupama, što doprinosi individualizaciji. Treće, ove fotografije počivaju na oneobičavanju običnog tako što svakodnevne radnje kontekstualizuju u ,izbeglički život", odnosno u širim planovima pozicioniraju nosioce radnje ističući tako kontrast između okruženja i same radnje. Na primer, na Slici 7 u prvom planu vidimo decu dok u drugom, zamagljenom vidimo šatore izbegličkog kampa u Idomeniju. Na Slici 8 scena šišanja postavljena je u polju, među razbacanim stvarima i sa kućama koje simbolizuju „normalni život“, negde u daljini.

\section{Konceptualni obrasci predstavljanja}

Deca, porodica, usamljenost, žica i simbolička drugost jesu topoi u kojima se statično predstavljaju izbeglice. Vizuelne reprezentacije dece i njihovih roditelja su najzastupljenijih jer, kako su i prethodna istraživanja ustanovila, oni predstavljaju žrtve dostojne pomoći (Lenette \& Cleland, 2016). Deca se uglavnom predstavljaju krupnim kadrovima, kao jedini (Slike 10 i 11) ili centralni (Slika 9) element kompozicije. Za razliku od drugih toposa u kojima se retko uspostavlja veza između interaktivnih i predstavljenih učesnika, deca na slikama najčešće se obraćaju gledaocu - vizuelno, usmeravanjem pogleda ili verbalnim porukama.

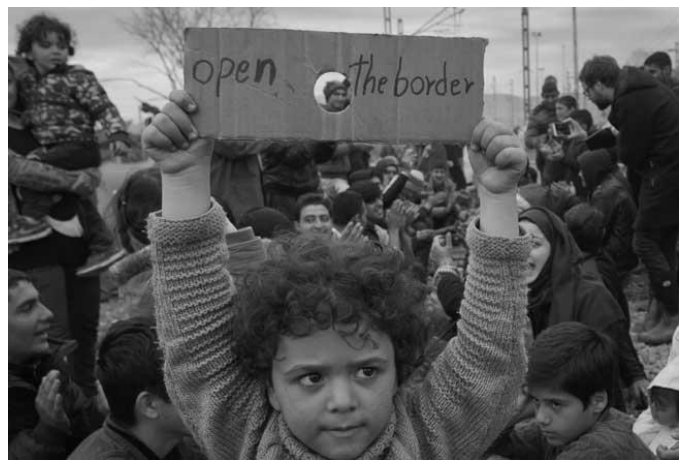

Slika 9. Topos deca

(Politika, 13. 3. 2016)

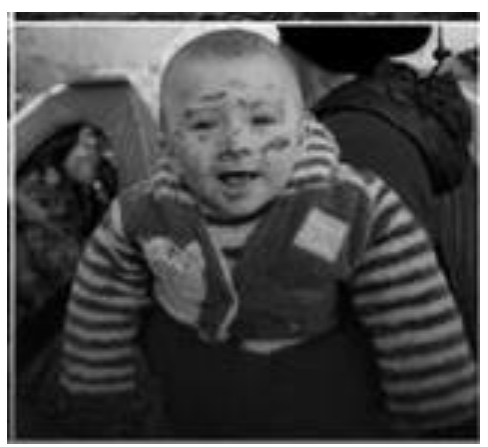

Slika 10. Topos deca

(Blic 11. 3. 2016, 15. 3. 2016) 


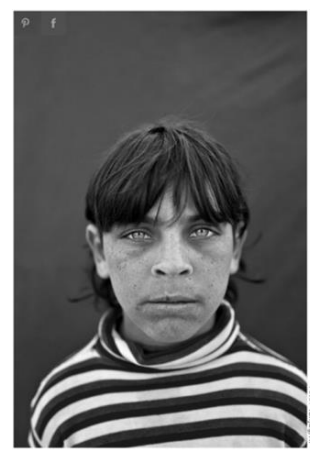

Slika 11. Topos deca (Blic, 12.3. 2016)

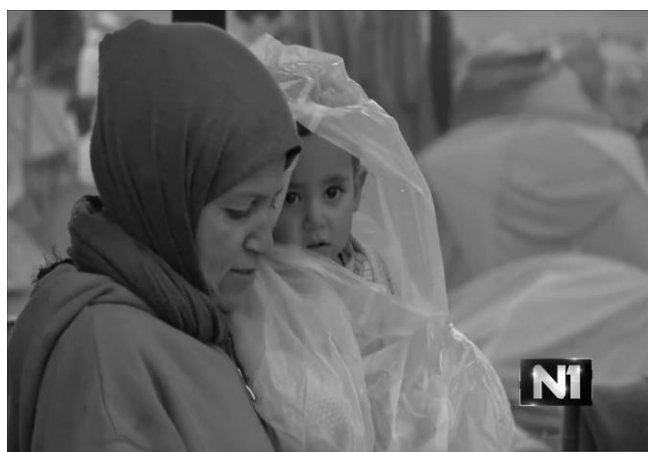

Slika 12. Topos porodica

(N1, 14. 3. 2016)

Galerija od 14 fotografija objavljena u Blicu pod nazivom „Ogledala užasa: Oči mališana koji su pobegli od rata u Siriji govore više od hiljadu reči“ potencira ideju da pogled deteta budi saosećanje. Međutim, ove fotografije odstupaju od obrasca prema kome su deca predstavljena u realnom okruženju, musava ili neadekvatno obučena. Klasifikacija dece kao „dece izbeglica“ u ostalim slikama ovde se transformiše, briše se kontekst i specifikacija, a na taj način univerzalizuje se prikaz. Drugim rečima, dok ostale fotografije govore „ovo su deca izbeglice“, galerija šalje poruku „ovo su deca“.

Jedina fotografija (Slika 13) koja se pojavljuje u oba perioda uzorkovanja (mart 2016, mart 2017) i uz sedam različitih tekstova jeste slika na kojoj su kombinovana tri toposa - topos dece, topos usamljenosti i topos žice. Topos usamljenosti realizuje se u kadrovima koji su zamućeni i u njima prikazani likovi pognute su glave (Slika 14) ili zamišljenog pogleda koji je usmeren negde daleko izvan okvira kadra (Slika 15). Usamljenost se prikazuje ponekad kao prostorna izolovanost od grupe (Slika 14) ili psihička izolacija kao u Slikama 14 i 15, na kojima zamišljeni pogled izvodi izbeglice izvan konteksta. 


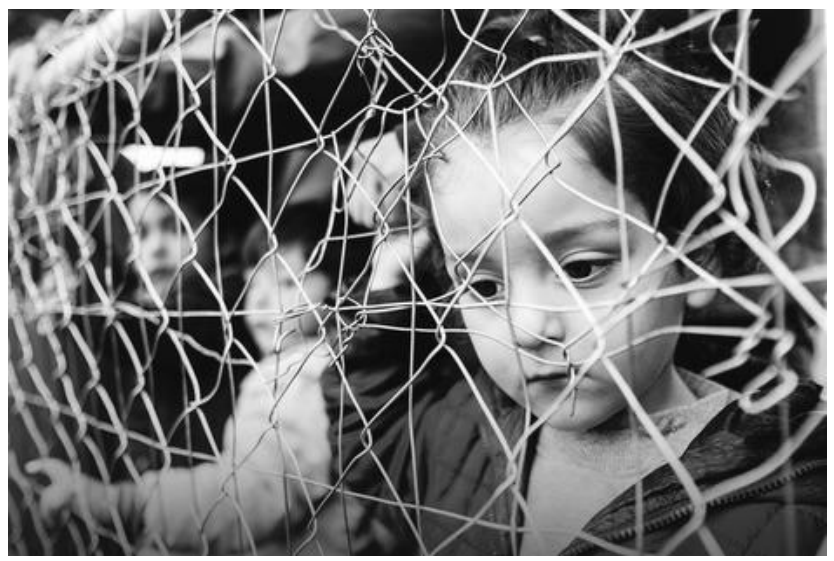

Slika 13. Topoi deca, usamljenost i žica

(Blic, 11. 3. 2016, 11. 3. 2016, 15. 3. 2016, 21. 3.

2017, 23. 3. 2017, 7. 3. 2017, 7. 3. 2017.

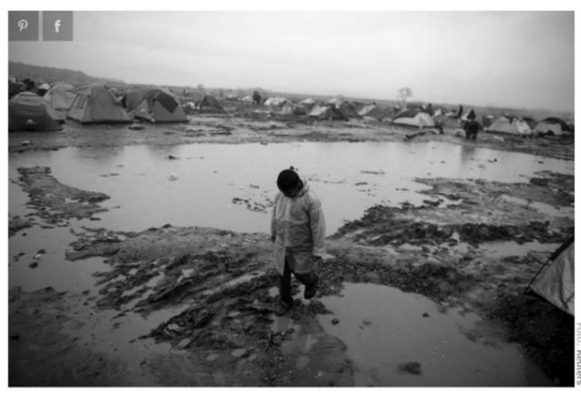

Slika 14. Topoi deca i usamljenost (Politika, 13. 3. 2016)

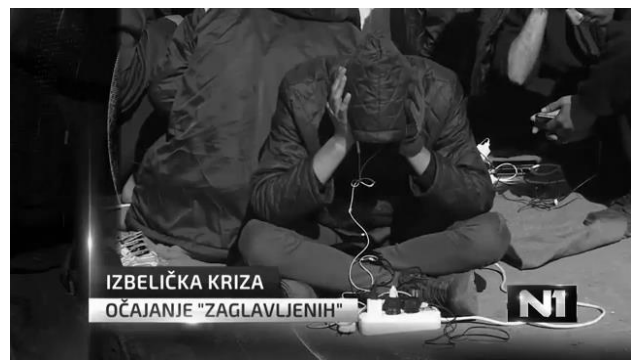

Slika 15. Topos usamljenosti (N1, 6. 3. 2017)

Žica se kao motiv pojavljuje u mnogim narativnim i konceptualnim reprezentacijama. U delu fotografija, kakav je slučaj sa Slikom 13, žica kojom se ograničava kretanje prestaje da bude detalj i dobija centralnu ulogu. U televizijskim prilozima žica može da se pojavi samostalno unutar kadra ili sekvence, na nivou detalja (Slika 17) ili, što je češće slučaj, na slikama se kontrastiraju žica i ljudsko telo u blizini (Slika 16). 


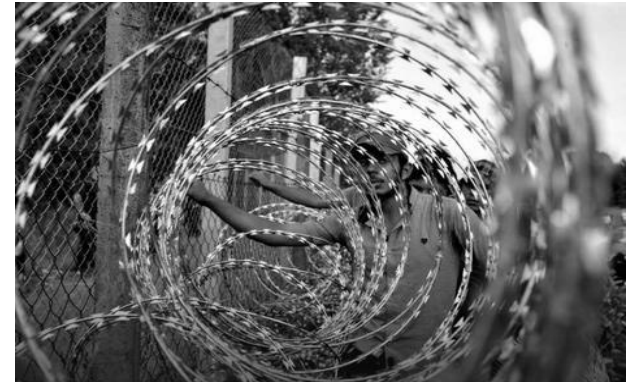

Slika 16. Topos žice - fotografija (Blic, 19. 3. 2017)

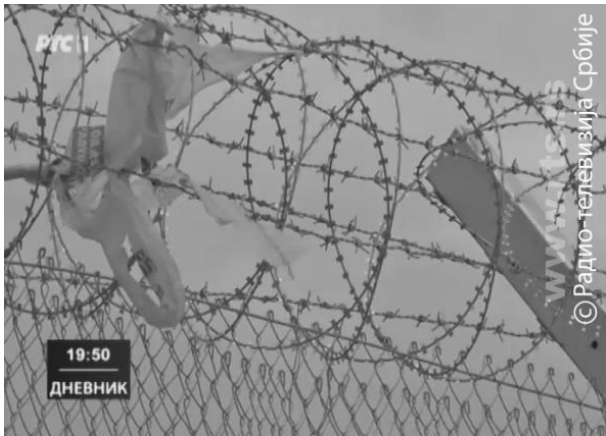

Slika 17. Topos žice - televizijski prilog (RTS, 13. 3. 2016)

Pored vizuelnih reprezentacija ljudi, postoje i slike koje posredno govore o njima, opisuju ih putem crtica iz izbegličkog života. Izrazito metaforičke predstave denotiraju nužnost života „u civilizovanom svetu“, poput odeće, obuće, hrane ili krova na glavom, a konotiraju njihov izostanak, manjak ili neadekvatnost. Tumačenje ovih slika počiva na znanju o tome šta čini običan i normalan život, a oni koji ga nemaju posredno se konstruišu kao Drugi. Ovako konstruisana drugost može se dalje čitati dvojako - kao različitost koja je privremena, koja je posledica prinudnih okolnosti i koja zahteva pomoć ili kao drugost koja je već postojeća, posledica drugačije kulture i životnih navika i koju treba odbaciti ili promeniti.

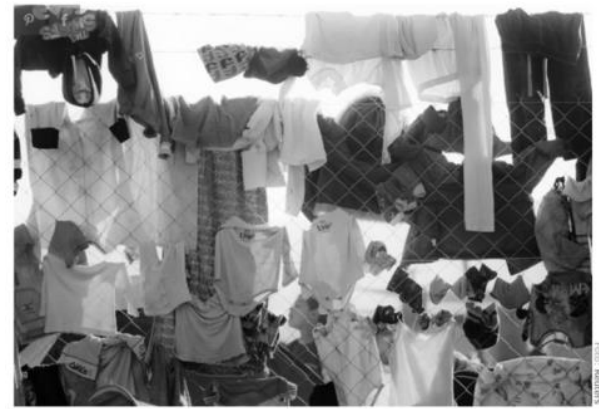

Slika 18. Topos simbolička drugost (Blic, 11.3. 2016)

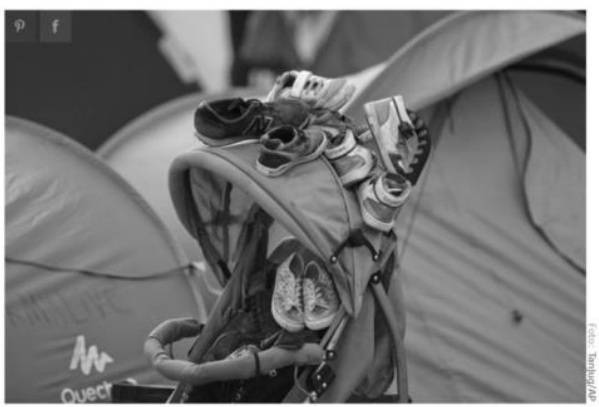

Slika 19. Topos simbolička drugost (Blic, 12. 3. 2016) 


\section{DISKUSIJA}

Vizuelni toposi kojim su predstavljene izbeglice na „Balkanskoj ruti“ pojavljuju se u narativnim i konceptualnim obrazaca predstavljanja. Razlike u njihovoj zastupljenosti u onlajn izdanjima dnevnih listova Blic i Politika i u televizijskim prilozima Radio-televizije Srbije i N1 neznatne su. Kretanje i drama, zajedno sa slikama dece, najfrekventniji su u svim analiziranim medijima. Međutim, kada se posmatraju dva perioda, mart 2016. godine i mart 2017. godine, mogu se uočiti razlike. Prvo, već u odnosu na broj TV priloga i tekstova, može se ustanoviti pad interesovanja za temu izbeglica. Čini se da je „zatvaranje“ pravca koji vodi preko Republike Srbije uspelo da smanji broj izbeglica, a time i medijsko interesovanje. Drugo, topos drame i primanja pomoći pojavljuje se samo tokom 2016. godine, dok tokom 2017. godine mediji češće izveštavaju o životu izbeglica smeštenih u Srbiji.

U celini posmatrani, topoi šalju kontradiktorne vizuelne poruke. Sa jedne strane, fotografije i prilozi predstavljaju direktne ili indirektne apele za saosećanjem, u čemu najznačajniju ulogu imaju slike dece, koje ponekad čak neskriveno persuazivno imaju ovaj cilj (npr. Slika 9). Topoi porodice, primanja pomoći i usamljenosti takođe opisuju izbeglice u kontekstu humanitarne krize koja zahteva humani odgovor. Međutim, pozivajući na saosećanje, vizuelne poruke održavaju distancu između predstavljenih subjekata i interakcijskih subjekata (fotoreportera, snimatelja i gledalaca). Ovo se naročito odnosi na one fotografije i slike izbeglica zabeležene iz gornjeg rakursa koji sam po sebi označava nemoć i slabost snimanog objekta. Izbeglice se iz ovog ugla posmatranja, odnosno kadriranja, stavljaju u poziciju objekta koji se gleda s visine, pružajući perspektivu pružaoca pomoći sa druge strane žice što gledaoca postavlja izvan okvira iskustva izbeglice i umanjuje mu mogućnost uspostavljanja empatije.

Lice izbeglice je prepoznatljivo kada se radi o ženama i deci, dok se slika muških lica pojavljuje onda kada treba da potencira dramatičnost događaja. Ujedno, muškarci su češće prikazani u većim grupama, dok je, kada se pojavljuje, lice deteta jedini element na slici. U retkim slučajevima kada je prikazan jedan muškarac, onda postoje drugi markeri koji ga reprezentuju kao žrtvu - povijeno telo (kao na Slici 15), krv na licu, ćebe u koje je zavijen, i slično. Na ovaj način mediji konstruišu dve grupe aktera - one sa kojima komuniciramo jer im vidimo lice i koji su dostojni podrške, i one koje ne raspoznajemo u masi pa i ne možemo sa njima da saosećamo.

Topos kretanja jedan je od najfrekventnijih, a njime se izbeglice predstavljaju kao kolektivni akteri svedeni na odlazak i dolazak. Snaga i žilavost ovog toposa potvrđuje se i u njegovoj verbalnoj realizaciji, u vidu metafora 
povezanih sa vodom („reka izbeglica“, „izbeglički talas“, „priliv“). Međutim, posmatrano kao vizuelna metafora, kretanje funkcioniše kao slika puta koji je dekontekstualizovan. On nema početak ni kraj (videti Slike 1 i 2), polazište kao osnovni referent za razumevanje događaja nije predstavljeno, a cilj je neizvestan i dalek, negde izvan okvira slike. Na taj način kretanje, to jest put, iako pripada narativnom obrascu, postaje stanje - ključna odrednica izbeglica.

Posmatrano u kontekstu prethodnih istraživanja, topos kretnja jedini je koji ima negativnu konotaciju, naglašenu u prikazima kretanja koje vodi ka „nama“. U četiri analizirana medija nije bilo slika na kojima su izbeglice predstavljene kao kriminalci, rušitelji granica i u lažnoj potrebi za pomoći. I kada se vizuelnim sredstvima konstruiše drugost, negativno vrednovanje nije eksplicirano nego je naznačeno kao mogući interpretativni pravac koji će zavisiti od prethodnih saznanja i stavova interpretatora.

\section{ZAKLJUČNE NAPOMENE}

Fotografije i televizijske slike, zajedno sa ostalim elementima vesti postavljaju ljude i događaje u interpretativne okvire (Tomanić Trivundža, 2015), nudeći svojoj publici određene perspektive. U tom kontekstu treba primetiti da podaci do kojih je došla agencija Prozitiv, pokazuju da je negativno mišljenje građana Srbije o izbeglicama poraslo sa 19 odsto u 2016. na 33 odsto u 2017. godini, dok pozitivan stav i empatiju prema izbeglicama u Srbiji danas ima 43 odsto građana, što je za 1,8 odsto manje nego na početku izbegličkog talasa (Stavovi građana Srbije prema izbeglicama, 2017: 2) ${ }^{2}$. Povećan strah od izbeglica logična je posledica izmenjenog načina medijskog izveštavanja, koje je na početku izbegličkog talasa bilo intenzivnije i pozitivnije.

U medijskom pristupu uočavaju se dva pristupa, jedan koji je motivisan željom za profitom, koji vodi senzacionalizmu i drugi u kojem se slike koriste ne samo da pobude pažnju javnosti, što je bio slučaj sa objavljivanjem fotografije Ajlana Kurdija u septembru 2015. godine, već da zaista obezbede pomoć. Prvi ilustruje tekst u britanskom Dejli mejlu sa fotografijom izbeglica koje po snegu čekaju na red za hranu u Beogradu, a ona se poredi sa starom fotografijom

${ }^{2}$ Tri ankete u periodu 2016-2017. sprovedela je agencija Propozitiv u svim mestima gde postoje prihvatni centri za migrante. Ukupan broj ispitanika u istraživanju sprovedenom 2017. godine iznosio je 2.700 osoba starih 15 i više godina, iz Beograda, Dimitrovgrada, Lajkovca, Preševa, Sjenice, Tutina, Subotice i Šida (za ostale izveštaje videti: https://www.divac.com/Razvoj-demokratije-i-podrska-lokalnimzajednicama/2113/PODRSKA-LOKALNIM-ZAJEDNICAMA-U-ODGOVORU-NA.shtml. 
nemačkih zarobljenika u Staljingradu 1943. godine, uz komentar da ove dve scene „zapanjujuće liče jedna na drugu“ (Dinham, 2017). Za razliku od ovog senzacionalističkog pristupa humanitarna kriza sa beogradskih ulica zabeležena na fotografijama imala je i drugačije odjeke u javnosti. Naime, serija fotografija koje je zabeležio fotograf Igor Čoko imala je važnu mobilizatorsku ulogu jer je prikupljena pomoć od 90 hiljada eura, novi mobilni toaleti, šatori, hrana, odeća.

Imajući u vidu ove različite pristupe, istraživanje predstavljeno u radu trebalo bi proširiti tako da se obuhvate raznovrsnije uređivačke konceptualizacije, od senzacionalističkih tabloida do alternativnih portala koji koriste slike volontera kako bi preneli utiske. Takođe, analiza medijskog izveštavanja o izbeglicama treba da se dopuni istraživanjem verbalnih poruka koje prate fotografije i televizijske slike pošto verbalni sadržaji mogu intenzivirati ili modifikovati vizuelne.

Jelena Kleut, Brankica Drašković

VISUAL REPRESENTATIONS OF THE REFUGEES ON THE "BALKAN ROUTE" IN THE SERBIAN MEDIA

Summary

This paper provides an analysis of representations of the refugees on the "Balkan route" in television images and news photographs. The aim of the paper is to identify how the refugees are represented in the country in which the refugee crisis is not politicized, and to examine how the refugees are represented in different modalities - static and moving images. The sample, consisting of 125 texts and television news stories, has been collected during seven days in March 2016 and in March 2017 from online editions of daily newspapers Blic and Politika, and from evening newscasts of Radio-television of Serbia and TV N1. The method of visual analysis is based on Kress and Van Leeuwen's visual grammar, and specifically on the analysis of visual topoi of representation. In terms of narrative patterns of representation we identify five topoi: drama, movement, receiving help, hygiene and play. Within conceptual patterns there are topoi of the family, children, loneliness, wire and symbolic otherness. More positive than in other countries, these visual representations are contradictory - although they call for compassion, they still construct otherness and the differences between "us" and "them".

Keywords: critical discourse analysis, multimodality, news photograph, television image, refugees, Serbia

\section{LITERATURA}

Alonso Belmonte, I., McCabe, A., \& Chornet-Roses, D. (2010). In their own words: The construction of the image of the immigrant in Peninsular Spanish 
broadsheets and freesheets. Discourse \& Communication, 4(3), 227-242. doi: $10.1177 / 1750481310373218$

Baker, P., Gabrielatos, C., KhosraviNik, M., Krzyzanowski, M., McEnery, T., \& Wodak, R. (2008). A useful methodological synergy? Combining critical discourse analysis and corpus linguistics to examine discourses of refugees and asylum seekers in the UK press. Discourse \& Society, 19(3), 273-306. doi: 10.1177/0957926508088962

Banks, J. (2012). Unmasking deviance: The visual construction of asylum seekers and refugees in English national newspapers. Critical Criminology, 20(3), 293-310. doi: 0.1007/s10612-011-9144-x

Berry, M., Garcia-Blanco, I., \& Moore, K. (2016). Press coverage of the refugee and migrant crisis in the EU: a content analysis of five European countries. Retrieved from http://orca.cf.ac.uk/id/eprint/87078.

Bischoff, C., Falk, F., \& Kafehsy, S. (Eds.). (2010). Images of illegalized immigration: towards a critical iconology of politics. Bielefeld: Transcript.

Bleiker, R., Campbell, D., Hutchison, E., \& Nicholson, X. (2013). The visual dehumanisation of refugees. Australian Journal of Political Science, 48(4), 398-416. doi: 10.1080/10361146.2013.840769

Caviedes, A. (2015). An Emerging ?European? News Portrayal of Immigration? Journal of Ethnic and Migration Studies, 41(6), 897-917. doi: 10.1080/1369183X.2014.1002199

Colombo, M. (2017). The Representation of the "European Refugee Crisis" in Italy: Domopolitics, Securitization, and Humanitarian Communication in Political and Media Discourses. Journal of Immigrant \& Refugee Studies, 1-18. doi: 10.1080/15562948.2017.1317896

Crespo Fernández, E., \& Martínez Lirola, M. (2012). Lexical and visual choices in the representation of immigration in the Spanish press. Spanish in Context, 9(1), 27-57. doi: 10.1075/sic.9.1.02cre

Dinham, P. (10. 1. 2017). Food queue with echoes of Europe's dark past: Freezing migrants wait for aid in Belgrade today in pictures chillingly similar to those from the Second World War. Daily Mail. URL: http://www.dailymail.co.uk/news/article-4107102/Belgrade-migrants-waitfood-pictures-similar-Second-World-War.html\#ixzz4mRV37cjr

Hodge, R., \& Kress, G. (1988). Social Semiotics. Cambridge: Polity

Höijer, B. (2004). The discourse of global compassion: The audience and media reporting of human suffering. Media, Culture \& Society, 26(4), 513-531. doi: 10.1177/0163443704044215 
Holmes, S. M., \& Castaneda, H. (2016). Representing the ?European refugee crisis? in Germany and beyond: Deservingness and difference, life and death: Representing the ?European refugee crisis? American Ethnologist, 43(1), 12-24. doi: 10.1111/amet.12259

Horsti, K. (2016). Visibility without voice: Media witnessing irregular migrants in BBC online news journalism. African Journalism Studies, 37(1), 1-20. doi: 10.1080/23743670.2015.1084585

Jenni, K., \& Loewenstein, G. (1997). Explaining the identifiable victim effect. Journal of Risk and Uncertainty, 14(3), 235-257.

Khosravinik, M. (2010). The representation of refugees, asylum seekers and immigrants in British newspapers: A critical discourse analysis. Journal of Language and Politics, 9(1), 1-28. doi: 10.1075/jlp.9.1.01kho

Kress, G. (2010). Multimodality: A social semiotic approach to contemporary communication. London: Routledge.

Kress, G., \& Van Leeuwen, T. (2001). Multimodal Discourse: The Modes and Media of Contemporary Communication. Arnold: London.

Kress, G., \& Van Leeuwen, T. (2006). Reading images: The grammar of visual design. 2nd Edition. London: Routledge.

Lalić, S. (2016). Uloga medija u oblikovanju javnog mnijenja prema izbjeglicama $i$ tzv. izbjegličkoj krizi. Zagreb: GONG - Kuća ljudskih prava Zagreb. URL: http://www.dostajemrznje.org/wp-content/uploads/2016/10/Uloga-medijau-oblikovanju-javnog-mnijenja-prema-izbjeglicama.pdf

Lenette, C., \& Cleland, S. (2016). Changing faces: Visual representations of asylum seekers in times of crisis. Creative Approaches to Research, 9(1), 68.

Lenette, C., \& Miskovic, N. (2016). 'Some viewers may find the following images disturbing': Visual representations of refugee deaths at border crossings. Crime, Media, Culture, doi: 10.1177/1741659016672716

Manchin, D., \& Mayr, A. (2012). How To Do Discourse Analysis: A Multimodal Introduction. London: Sage.

Mannik, L. (2012). Public and private photographs of refugees: the problem of representation. Visual Studies, 27(3), 262-276. doi: 10.1080/1472586X.2012.717747

Martinez Lirola, M. (2014). Exploring visual dysphemisms in pieces of news related to immigrant minors in a Spanish newspaper. Visual Communication, 13(4), 405-427. doi: 10.1177/1470357214541741

O'Halloran, K. L. (2004). Multimodal Discourse Analysis. Systemic-Functional Perspectives. London: Continuum. 
Pozitivan stav prema migrantima ima 43 odsto građana Srbije (19. 6. 2017). Insajder. URL: https://insajder.net/sr/sajt/vazno/5357/Pozitivan-stavprema-migrantima-ima-43-odsto-gra\%C4\%91ana-Srbije.htm

Reisigl, M. \& Wodak, R. (2001). Discourse and discrimination: Rhetorics of Racism and Antisemitism. London: Routledge.

Rheindorf, M., \& Wodak, R. (2017). Borders, Fences, and Limits?Protecting Austria From Refugees: Metadiscursive Negotiation of Meaning in the Current Refugee Crisis. Journal of Immigrant \& Refugee Studies, 1-24. doi: 10.1080/15562948.2017.1302032

Richardson, J., \& Colombo, M. (2013). Continuity and change in anti-immigrant discourse in Italy: An analysis of the visual propaganda of the Lega Nord. Journal of Language and Politics, 12(2), 180-202. doi: 10.1075/jlp.12.2.02ric

Scheufele, D. (1999). Framing as a theory of media effects. Journal of Communication, 42(1): 103-122.

Stavovi građana Srbije prema izbeglicama (2017). Fondacija Ana i Vlade Divac. URL: https://www.divac.com/upload/document/trifold_srpski_preview.pdf-

Szörényi, A. (2006). The images speak for themselves? Reading refugee coffeetable books. Visual Studies, 21(1), 24-41. doi: 10.1080/14725860600613188

Tomanić Trivundža, I. (2015). Press Photography and Visual Framing of the News. Ljubljana: Faculty of Social Sciences.

Van Dijk, T. A. (1988) News as Discourse. Hillsdale: Lawrence Erlbaum.

Van Leeuwen, T. (2008). Discourse and Practice: New Tools for Critical Discourse Analysis. Oxford University Press.

Vuletić, V., Stanojević, D., Vukelić, J., \& Pešić, J. (2016). Studija o izbeglicama Srbija 2016. Beograd: Friedrich Ebert Stiftung - Centar za primenjena društvena istraživanja. URL: http://library.fes.de/pdffiles/bueros/belgrad/12928.pdf.

Wright, T. (2002). Moving images: The media representation of refugees. Visual Studies, 17(1), 53-66. doi: 10.1080/1472586022000005053 
